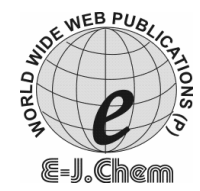

\title{
Preparation, Spectroscopy, Physicochemical Properties and X-ray Structure Analysis of 3,4,5-Trimethoxy $N$-(2-hydroxybenzylidene) aniline
}

\author{
KODJO CHARLES GUILLAUME*, ZABRI HERVE, \\ BENIE ANOUBILE and ESTIENNE JACQUES ${ }^{\S}$ \\ Laboratoire de chimie bio-organique et de substances naturelles, UFR-SFA, \\ Université d'Abobo-adjamé, 02 B.P. 801 Abidjan 02, Côte d'Ivoire. \\ ${ }^{\S}$ Laboratoire de Spectrométries et Physico-Chimie Structurale, Université Paul Cézanne Aix- \\ Marseille III, Centre de Saint Jérôme, case 242, 13397 Marseille cedex 20 France. \\ charles.kodjo@yahoo.fr
}

Received 5 February 2009; Accepted 4 April 2009

\begin{abstract}
Trimethoxy $N$-(salicylidene) aniline was synthesized and characterized by IR spectroscopy, ${ }^{1} \mathrm{H}$ NMR and x-ray single crystal analysis. UV-visible spectroscopy was used for physicochemical tests. X-ray data reveals that the crystalline network cohesion of this compound is essentially assured by $\mathrm{CH} / \mathrm{pi}$ type hydrogen bounds. It crystallized in the orthorhombic $\mathrm{Pbcn}$ space group. Electronic spectroscopy shows that the title compound doesn't present photochromic property but thermochromic one. Intermolecular interactions analysis confirms for this compound a thermochromic structural predisposition.
\end{abstract}

Keywords: Salicylideneaniline, X-ray structure, $\mathrm{CH} / \mathrm{Pi}$ hydrogen bound, Thermochromic, photochromic.

\section{Introduction}

There have been a number of structural studies on crystalline $N$-salicylideneaniline and its substituted derivatives, in connection with the tautomerism by hydrogen transfer observed in the molecular materials. Indeed, they provide useful models for the investigation of molecular geometry and electronic to determine the mechanistic aspects of thermo induced (thermochromism) or photo induced (photochromism) colour change phenomenon, respectively with temperature or with ultraviolet irradiation. According the literature, in addition to the proton transfer, $180^{\circ}$ rotation of the salicylidene moiety would be necessary for the demonstration of photochromic property ${ }^{1-4}$. Moreover, $N$-salicylideneanilines exhibit 
polymorphism and the existence of a wide range of different crystal packing modes among this class of compound induce us to focus not only on the role of the chromophore but to pay attention to topochemical aspects and crystal packing, in order to develop a global crystallochromy analysis ${ }^{5}$. Indeed, this approach would permit to better understand the mechanisms that orient a compound toward one or the other of these two properties in order to be able to predict them. In recent years the basic research on solid photochromic materials is growing since, in addition to scientific interest, there is considerable commercial interest in areas such as communications, computers, microfilm and display systems ${ }^{6}$. During the course of our systematic structural investigation of Schiff bases, it was suggested that the introduction of methoxy substituents with a large degree of floppiness into salicylideneanilines would be effective in producing photochromic crystals. Consequently, in this paper, we have synthesized the title compound introducing three methoxy substituents in the positions 3, 4 and 5 on the aniline phenyl ring for the determination of the effects of these substituents in these positions on the photochromism of Schiff bases.

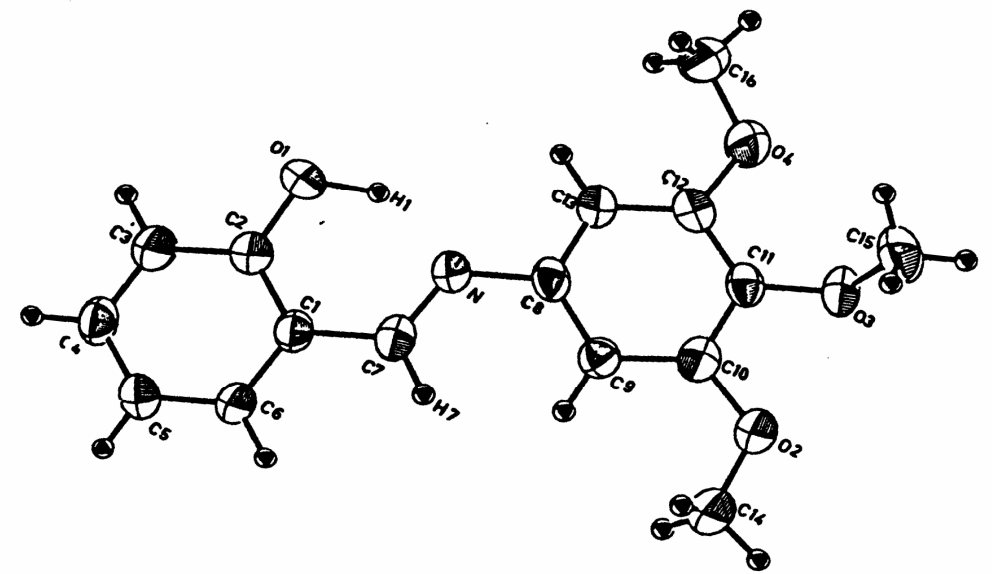

Figure 1. Molecular structure of 3,4,5-trimethoxy $N$-(2-hydroxybenzylidene) aniline with atomic numbering scheme. (Displacement ellipsoids are drawn at $50 \%$ probability level).

\section{Experimental}

2-Hydroxybenzaldehyde and 3,4,5-trimethoxyaniline were procured from Aldrich and used without further purification. All the solvents were dried before use. Melting points were determined in capillary tube using an MPD Mitamura Riken Kogyo (Japan) electrothermal melting point apparatus and are uncorrected. IR spectra in the range $4000-400 \mathrm{~cm}^{-1}$ were obtained on a Mattson 1000 FTIR spectrophotometer, with samples investigated as $\mathrm{KBr}$ disks. The ${ }^{1} \mathrm{H}$ spectra were recorded on a Bruker AMX-400 spectrometer, operating at $400 \mathrm{MHz}$. UV-visible spectra were obtained on an UV4 model of ATI UNICAM spectrometer. For the photochromic tests, the samples were radiated by an UV selected radiation $(\lambda=365 \mathrm{~nm})$.

\section{Synthesis}

The title compound has been synthesized by reflux heating in dry ethanol $(40 \mathrm{~mL})$ of a mixture of 2-hydroxybenzaldehyde $(4 \mathrm{~mL})$ and 3,4,5-trimethoxyaniline $(7 \mathrm{~g})$ for about $1 \mathrm{~h}$. The reaction mixture has been cooled in an ice bath until the title compound precipitated as a yellow solid. The solid was then recrystallized from ethanol, (yield: $90 \%$, mp 80-81 ${ }^{\circ} \mathrm{C}$ ). A good quality of single crystals was obtained by slow evaporation of a methanol solution. 
Analysis

${ }^{1} \mathrm{H}$ NMR $\left(\mathrm{CDCl}_{3}, 400 \mathrm{MHz}\right) \delta, 13.18(\mathrm{~s}, 1 \mathrm{H}, \mathrm{OH}), 6.94(\mathrm{~m}, 1 \mathrm{H}$ aromatic), $7.39(\mathrm{~m}, 1 \mathrm{H}$ aromatic), 6.98 (m, 1H aromatic), $7.56(\mathrm{~m}, 1 \mathrm{H}$ aromatic), $8.93(\mathrm{~s}, 1 \mathrm{H}), 6.80(\mathrm{~s}, 2 \mathrm{H}$ aromatic), 3.89 (s, 6H Me), 3.75 (s, 3H Me); IR (KBr, cm $\left.{ }^{-1}\right), 2500-2800 v(\mathrm{O}-\mathrm{H}), 1613 v(\mathrm{C}=\mathrm{N})$,

\section{Results and Discussion}

$X$-ray analysis

The predictions on the basis of spectroscopic data are entirely borne out in the structure of the title compound, as determined by x-ray diffraction. Figure 1 shows the title molecule with the atom-numbering scheme. The crystal data and the selected bond lengths and angles are given in Tables 1 and 2, respectively. The dihedral angles between the different mean plans are given in Table 3 . The weak value of $\alpha$ dihedral angle is in the usual ranges ${ }^{7-8}$ and encourage the closeness of oxygen atom $\mathrm{O}_{1}$ and nitrogen atom. Compared to the standards values proposed by Allen et al. ${ }^{9}$, the title compound with $\mathrm{C}_{1}-\mathrm{C}_{7}[1.443(6) \AA], \mathrm{C}_{7}=\mathrm{N}$ $[1.278(5) \AA]$ and $\mathrm{C}_{2}-\mathrm{O}_{1}[1.350(5) \AA]$ bonds is at $82 \%$ phenolic tautomer. The longer $\mathrm{O}_{1}{ }^{\cdots} \mathrm{N}$ intramolecular distance $[2.565(8) \AA]$ is significantly less than the sum of the van der Waals radii $[3.07 \AA]$. It implies a strong $\mathrm{O}_{1}-\mathrm{H}_{1} \cdots \mathrm{N}$ intramolecular hydrogen bond. The torsion angles values of $\tau_{\mathrm{C} 14-\mathrm{O} 2-\mathrm{C} 10-\mathrm{C} 9}=5^{\circ}, \tau_{\mathrm{C} 16-\mathrm{O} 4-\mathrm{C} 12-\mathrm{C} 13}=7^{\circ}$ and $\tau_{\mathrm{C} 15-\mathrm{O} 3-\mathrm{C} 11-\mathrm{C} 10}=-95^{\circ}$ gotten indicate that, with a $\tau$ value close to $90^{\circ}$, only the central methoxy group adopts out-of-plane conformation. The two lateral methoxy groups lie close to the aniline nucleus plane.

Table 1. Crystal, data collection, and structure refinement parameters.

\begin{tabular}{ll}
\hline Empirical formula: $\mathrm{C}_{16} \mathrm{H}_{17} \mathrm{O}_{4} \mathrm{~N}$ & Temperature: $293 \mathrm{~K}$ \\
Formula weight: 287.32 & 194 parameters \\
$\mathrm{X}$-ray: MoK $\alpha$ & 2381 independente reflexions \\
Crystal system: Orthorhombic & 1227 observed reflexions \\
Space group: $\mathrm{Pbcn} \mathrm{Z}=8$ & Index ranges: $\mathrm{h}=0 \rightarrow 12 \mathrm{k}=0 \rightarrow 16 \mathrm{l}=0 \rightarrow 22$ \\
$\mathrm{a}=10.532(2) \AA$ & Theta range for data collection: $8.78^{\circ} \leq \theta \leq 12.28^{\circ}$ \\
$\mathrm{b}=14.742(3) \AA$ & Refinement on $\mathrm{F} 2,[\mathrm{I}>2 \sigma(\mathrm{I})]$ \\
$\mathrm{c}=19.567(3) \AA$ & Final R indices $: \mathrm{R}_{1}=0.0545 \mathrm{wR}_{2}=0.1413$ \\
$\alpha=\beta=\gamma=90^{\circ}$ & $\mathrm{R}$ indices ( all data $): \mathrm{R}_{1}=0.1482 \mathrm{wR}_{2}=0.2427$ \\
$\mathrm{v}=3038.0(1) \AA^{3}$ & Goodness of fit $: 1.075$ \\
$\mathrm{D}_{\mathrm{x}}=1.256 \mathrm{Mgm}^{-3}$ & Enraf-Nonius CAD-4 diffractometer \\
Absorption coefficient: $0.091 \mathrm{~mm}^{-1}$ & Structure determination: SHELXS 97 \\
\hline
\end{tabular}

The analysis of the crystalline stacking (Figure 2) watch that the two aromatic nucleus of the salicylidene moieties of the molecules ( 1 and 2 ), are in face to face configuration with $3.54 \AA$ mean distance. This short plan to plan distance observed inside this crystal, excluded all important rotation possibility of the salicylidene moieties for the demonstration of photochromic property. The relative short mean distance observed between the hydrogen atom $\mathrm{H}_{4}$ attached to the $\mathrm{C}_{4}$ carbon atom of the molecule 3 and the mean plan of the aromatic nucleus of the fragment 3,4,5-trimethoxybenzene of the molecule $1(\mathrm{~d}=2.78 \AA)$, describe $\mathrm{C}-\mathrm{H} \cdots \pi($ arene $)$ type interaction. According to several authors ${ }^{10-12}, \mathrm{CH} /$ pi interactions can play an important role in the orientation of the crystalline stacking and the molecular structures topographies. The crystalline stacking of the title compound shows around each $2_{1}$ cristallographic symmetry axis « herring-bone » structures ${ }^{13}$. Along the $\mathrm{C} 2$ symmetry axis, the molecules are associated in infinite chain through $\mathrm{C}_{4}-\mathrm{H}_{4} \cdots \pi$ hydrogen bonds. These $\mathrm{CH} / \mathrm{Pi}$ interactions participate efficiently in the stabilization of the crystalline structure in this direction. In the centrosymetric dimer constituted by the 
molecules 1 and 4 , one of the three hydrogen atoms linked to $\mathrm{C}_{16}$ carbon atom of one molecule, is in interaction with the six carbon atoms of the aromatic moiety of the 3,4,5-trimethoxybenzene fragment of the other molecule. These other $\mathrm{C}-\mathrm{H}^{\cdots} \pi(\operatorname{arene})$ type interactions, with a shorter mean distance $\mathrm{d}=2.65 \AA$, contribute efficiently to assure the cohesion between the different group of molecule in cluster around the different C2 symmetry axis. Consequently, every trimethoxylated phenyl ring is hired as hydrogen bonds acceptor, in a double hydrogen bonds interactions according to the diagram $\mathrm{C}-\mathrm{H}{ }^{\cdots} \pi \cdots \mathrm{H}-\mathrm{C}$. The three methoxy groups introduced on the aniline ring, particularly the central substituent in the out-of-plane conformation, don't seem to act as space opener in the crystal lattice to permit the demonstration of the photochromic property.

Table 2. Selected bond lengths and angles $\left(\AA{ }^{\circ}{ }^{\circ}\right)$.

\begin{tabular}{llll}
\hline $\mathrm{C}_{1}-\mathrm{C}_{2}$ & $1.391(7)$ & $\mathrm{C}_{2}-\mathrm{C}_{1}-\mathrm{C}_{7}$ & $120.5(5)$ \\
$\mathrm{C}_{1}-\mathrm{C}_{6}$ & $1.386(6)$ & $\mathrm{C}_{1}-\mathrm{C}_{2}-\mathrm{O}_{1}$ & $121.1(4)$ \\
$\mathrm{C}_{2}-\mathrm{C}_{3}$ & $1.387(7)$ & $\mathrm{C}_{2}-\mathrm{C}_{3}-\mathrm{C}_{4}$ & $119.1(5)$ \\
$\mathrm{C}_{3}-\mathrm{C}_{4}$ & $1.362(7)$ & $\mathrm{C}_{3}-\mathrm{C}_{4}-\mathrm{C}_{5}$ & $120.8(5)$ \\
$\mathrm{C}_{4}-\mathrm{C}_{5}$ & $1.367(8)$ & $\mathrm{C}_{4}-\mathrm{C}_{5}-\mathrm{C}_{6}$ & $120.4(5)$ \\
$\mathrm{C}_{5}-\mathrm{C}_{6}$ & $1.372(8)$ & $\mathrm{C}_{1}-\mathrm{C}_{6}-\mathrm{C}_{5}$ & $121.8(5)$ \\
$\mathrm{N}-\mathrm{C}_{8}$ & $1.423(6)$ & $\mathrm{C}_{1}-\mathrm{C}_{7}-\mathrm{N}$ & $121.8(4)$ \\
$\mathrm{C}_{8}-\mathrm{C}_{9}$ & $1.390(6)$ & $\mathrm{N}-\mathrm{C}_{8}-\mathrm{C}_{9}$ & $116.4(4)$ \\
$\mathrm{C}_{8}-\mathrm{C}_{13}$ & $1.379(6)$ & $\mathrm{C}_{8}-\mathrm{C}_{9}-\mathrm{C}_{10}$ & $119.3(5)$ \\
$\mathrm{C}_{9}-\mathrm{C}_{10}$ & $1.382(6)$ & $\mathrm{C}_{9}-\mathrm{C}_{10}-\mathrm{C}_{11}$ & $120.3(4)$ \\
$\mathrm{C}_{10}-\mathrm{C}_{11}$ & $1.388(7)$ & $\mathrm{C}_{10}-\mathrm{C}_{11}-\mathrm{C}_{12}$ & $120.0(4)$ \\
$\mathrm{C}_{11}-\mathrm{C}_{12}$ & $1.377(7)$ & $\mathrm{C}_{11}-\mathrm{C}_{12}-\mathrm{C}_{13}$ & $120.3(5)$ \\
$\mathrm{C}_{12}-\mathrm{C}_{13}$ & $1.387(6)$ & $\mathrm{C}_{8}-\mathrm{C}_{13}-\mathrm{C}_{12}$ & $119.0(4)$ \\
\hline
\end{tabular}

Table 3. Dihedral angles $\left({ }^{\circ}\right)$

\begin{tabular}{cc}
\hline $\mathrm{I} / \mathrm{III}(\alpha)$ & $\mathrm{II} / \mathrm{III}(\beta)$ \\
\hline 4.9 & 28.3 \\
\hline
\end{tabular}

Mean plan I: C1,C2,C3,C4,C5,C6; Mean plan II: C8,C9,C10,C11,C12,C13; Mean plan III: C1,C7,N,C8

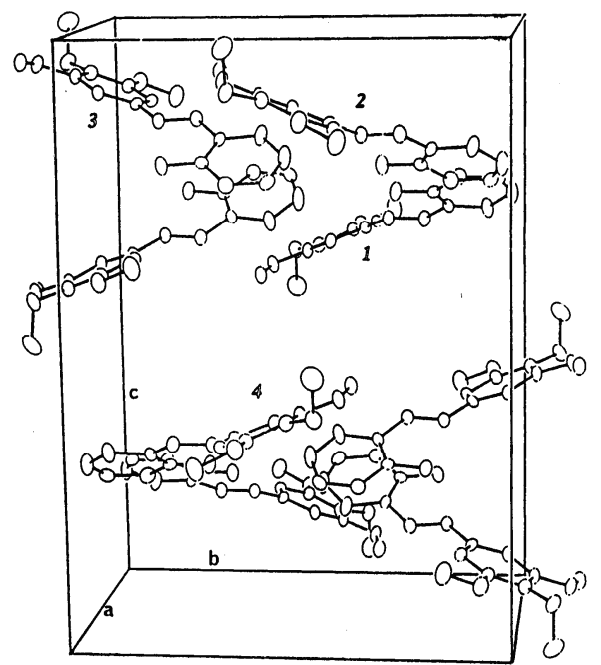

Figure 2. Packing diagram of 3,4,5-trimethoxy $N$-(2-hydroxybenzylidene) aniline. 


\section{Physicochemical properties}

UV-visible spectroscopy seems to be the best approach to analyze these properties. In order to allow the registration of the spectrum in solid state, sufficiently thin and transparent films of the compound were prepared on quartz plates. In the region 400-550 nm, UV-visible spectrum reveal at room temperature, a large absorption band named «thermochromic band $»^{2}$. It characterizes the $\pi$ system of the quinonic form $(\mathrm{Q})$ presents in the solid state in balance with the phenolic tautomer $(\mathrm{P})$. In order to verify the thermochromic property of the title compound, the test has been achieved at liquid nitrogen temperature $\left(-196{ }^{\circ} \mathrm{C}\right)$. The spectrum illustrated by the Figure 3 shows clearly the disappearance of the "thermochromic band". This important result permits to affirm that the title compound presents thermochromic property. For the photochromic property test, the compound has been irradiated with $\lambda=365 \mathrm{~nm}$ radiation situated inside the $\pi-\pi^{*}$ electronic transition of its $\mathrm{P}$ form. At room temperature where the compound was irradiated, no modification of the spectrum has been observed. In these conditions we conclude that 3,4,5-trimethoxy $N$ (salicylidene) aniline is not a photochromic compound.

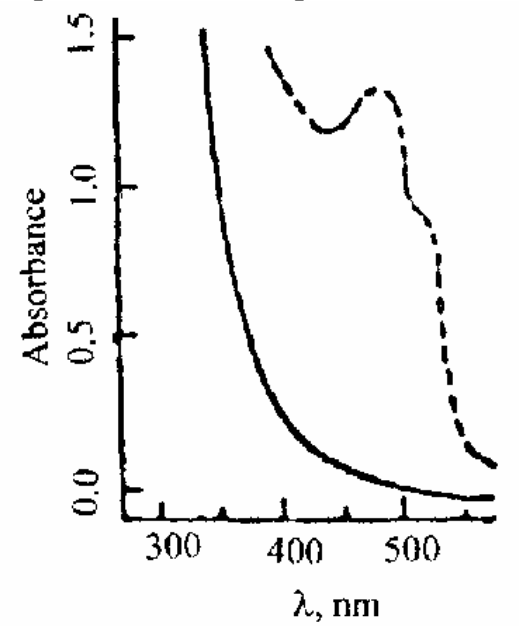

Figure 3. Absorption spectrum of 3,4,5-trimethoxy $N$-(2-hydroxybenzylidene) aniline at room temperature (---) and in liquid nitrogen (-).

\section{Conclusion}

3,4,5-Trimethoxy $N$-(2-hydroxybenzylidene) aniline was easily synthesized and characterised by spectroscopy methods. The stacking analysis reveals that the crystalline network cohesion is essentially controlled by $\mathrm{CH} /$ pi type hydrogen bounds. $3.54 \AA$ plan to plan mean distance observed inside this crystal excluded all important rotation possibility of the salicylidene moieties for the photochromic property demonstration. Uv-visible spectroscopy confirms that this compound presents exclusively thermochromic property. So, the introduction of methoxy substituents in the positions 3, 4 and 5 on the aniline nucleus doesn't have any effect on the photochromic porterty.

\section{Supplementary material}

Crystallographic data for the structural analysis have been deposited at the Cambridge Crystallographic Data Centre, CCDC No. 641476. Copies of this information may be obtained free of charge from the Director, CCDC, 12 Union Road, Cambridge, CBZ1E Z, UK (Fax: +44-1223-336033; email: deposit@ccdc.cam.ac.uk or http://www.ccdc.cam.ac.uk). 


\section{References}

1 Cohen M D, Schmidt G M and Flavian S, J Chem Soc., 1964, 2041.

2 Hadjoudis E and Moustakali-Mavridis I, Mol Cryst Liq Cryst., 1990, 31, 186.

3 Mansilla-Koblavi F, "Demonstration of tautomeric balance in a series of N (2, 3dihydroxybenzilidene) amines", $\mathrm{Ph} \mathrm{D}$ Thesis, 1993, N 187/93, Cocody University, Abidjan-Côte d'Ivoire.

4 Bregman J, Leizerowitz L and Osaki K, J Chem Soc., 1964, 2086.

5 Kodjo C G, "Structural determination of a series of 3,4,5-triméthoxy N-salicylidène anilines by x-ray diffraction and spectrometries", Ph D Thesis, 1997, $\mathrm{N}^{\circ} 97$ aix1 1011, Provence University, Marseille-France.

6 Ferraro A, "Design, synthesis and study of organic systems with photochromic properties", Ph D Thesis, 2000, N 00Bor1 0503, Bordeaux 1 University, BordeauxFrance.

$7 \quad$ Kodjo C G, Estienne J, Ziao N and Tenon J A, Phys Chem News, 2008, 39, 121.

8 Tenon J A, Kodjo C G, Carles M and Aycard J P, J Chem Cryst., 1999, 29, 111.

9 Allen F H, Kennard O and Wattson D G, J Chem Soc Perkin Trans., 1987, 2, S1.

10 Takahashi O, Saito K, Kohno Y, Suezawa H, Ishihara S and Nishio M, Eur J Org Chem., 2004, 2398.

11 Leigh D A, Linnane P, Pritchard R G and Jackson G, J Chem Soc Commun., 1994, 389.

12 Steiner T and Saenger W, J Chem Soc Commun., 1995, 2087.

13 Kitaigoroski A I, Molecular Crystals and Molecules; Academic press: London, 1973. 


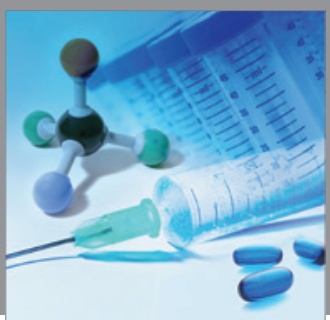

International Journal of

Medicinal Chemistry

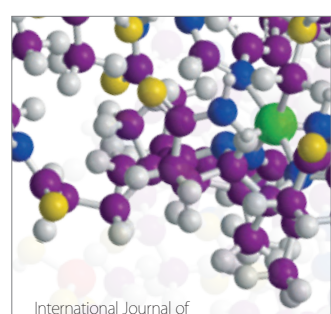

Carbohydrate Chemistry

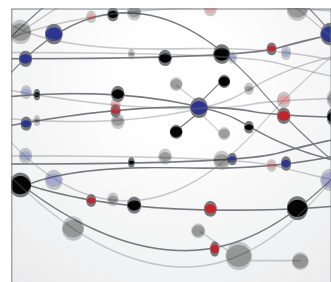

The Scientific World Journal
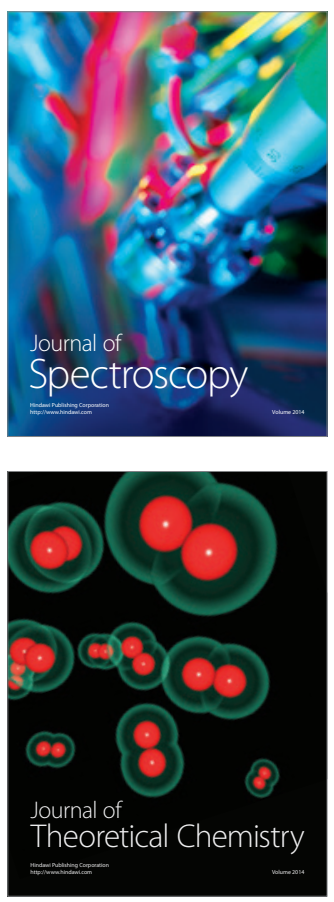
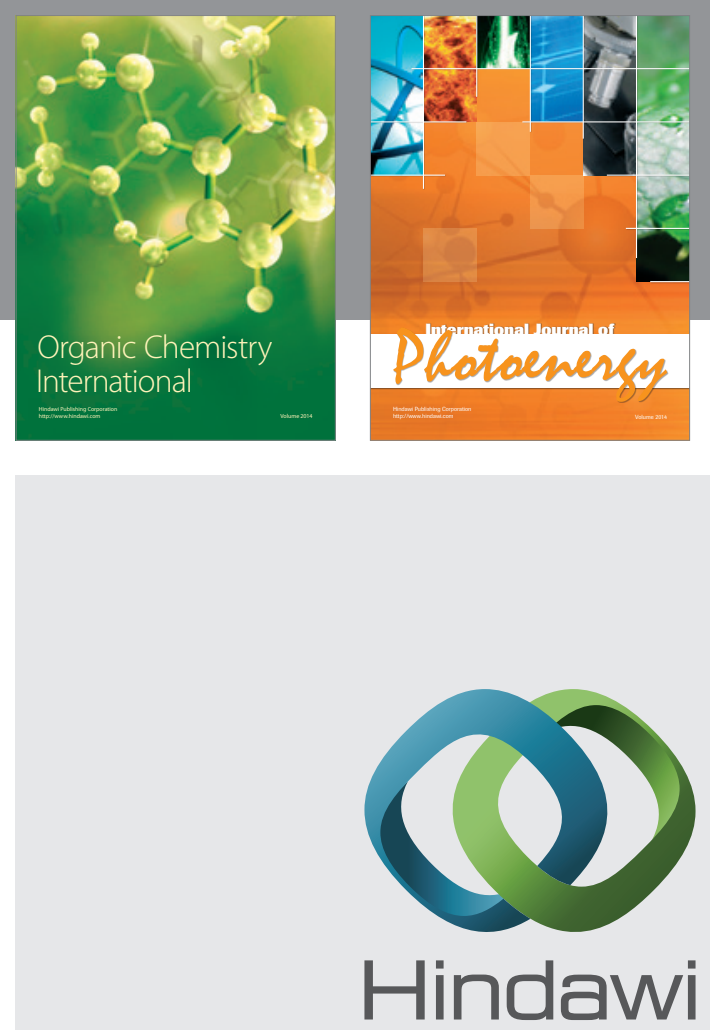

Submit your manuscripts at

http://www.hindawi.com
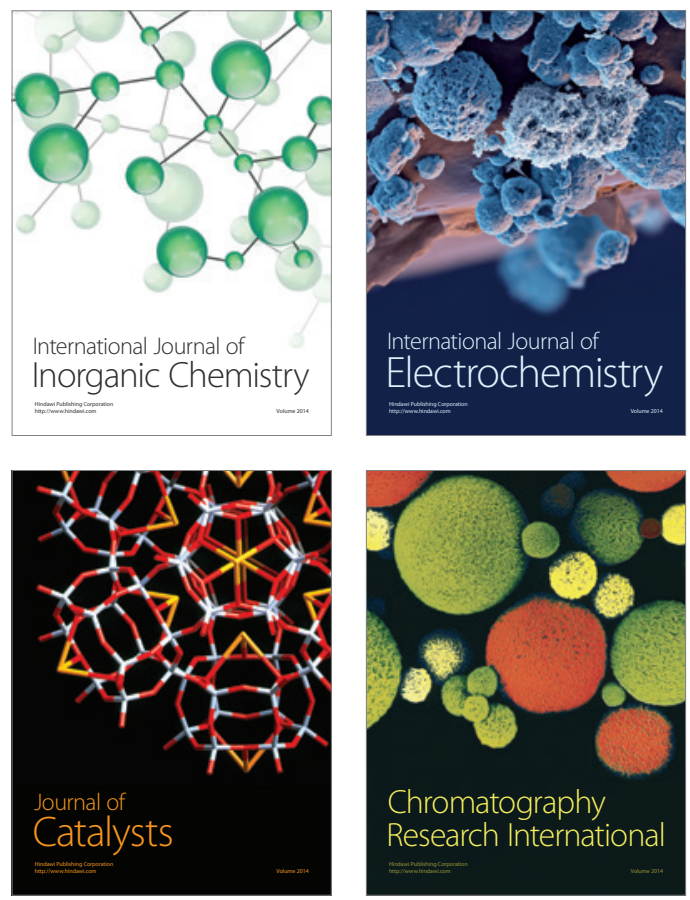
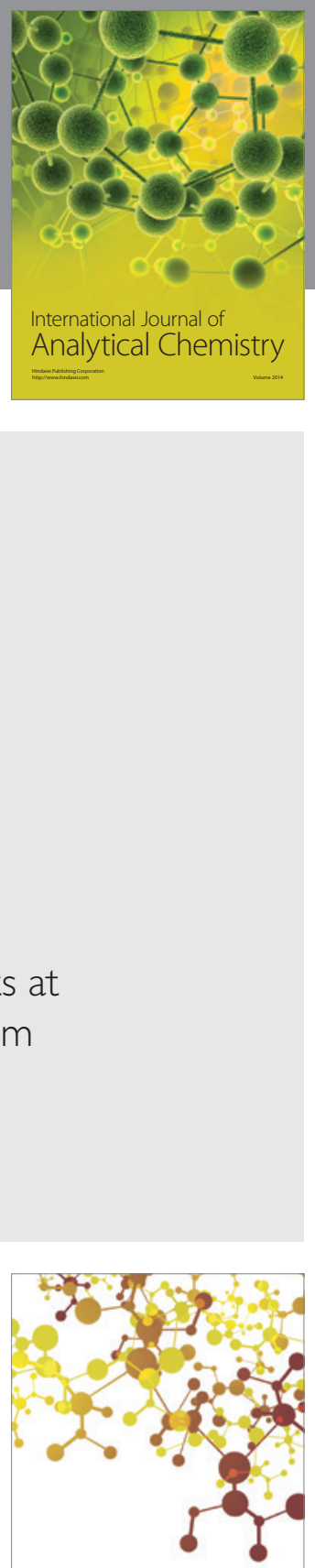

Journal of

Applied Chemistry
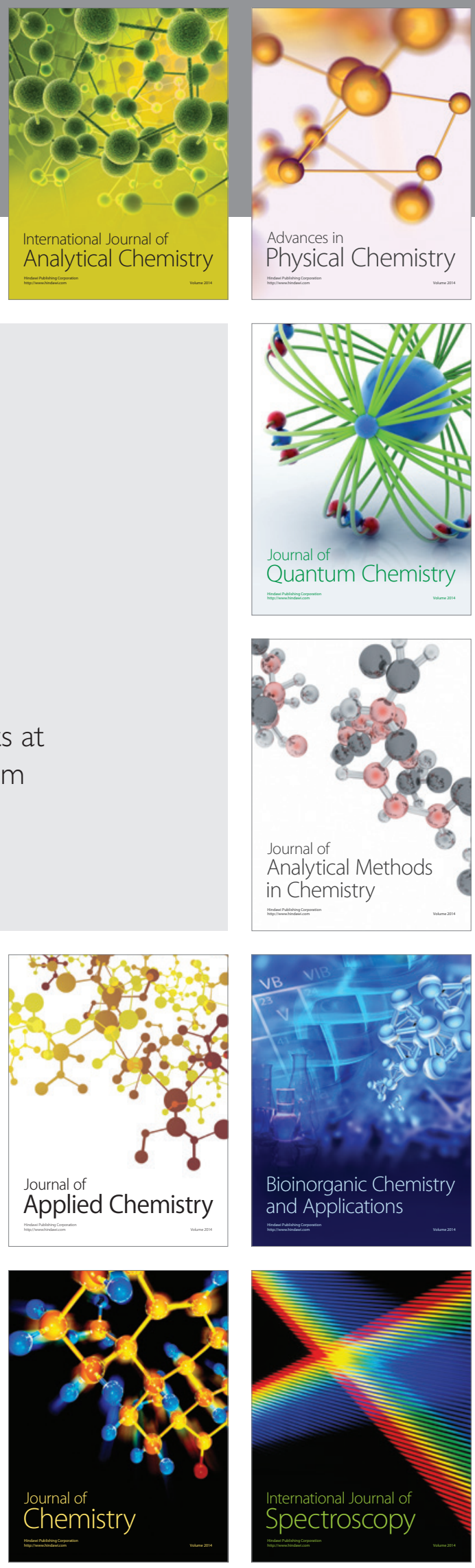